\title{
Corpus
}

Archivos virtuales de la alteridad americana

Vol 5, No 2 2015

Julio / Diciembre 2015

\section{Comentarios a los trabajos de Norma Ratto y José María Vaquer}

Ana María Lorandi

\section{OpenEdition}

\section{Journals}

\section{Electronic version}

URL: http://journals.openedition.org/corpusarchivos/1509

DOI: 10.4000/corpusarchivos.1509

ISSN: $1853-8037$

\section{Publisher}

Diego Escolar

\section{Electronic reference}

Ana María Lorandi, «Comentarios a los trabajos de Norma Ratto y José María Vaquer », Corpus [En línea], Vol 5, No 2 | 2015, Publicado el 17 diciembre 2015, consultado el 01 mayo 2019. URL : http:// journals.openedition.org/corpusarchivos/1509; DOI : 10.4000/corpusarchivos.1509

This text was automatically generated on 1 May 2019.

Licencia Creative Commons: Atribución-NoComercial 2.5 Argentina (CC BY-NC 2.5 AR) 


\title{
Comentarios a los trabajos de Norma Ratto y José María Vaquer
}

\author{
Ana María Lorandi
}

1 Para plantear la problemática sobre su zona de investigación en relación con las consignas que convocaron este encuentro, Norma Ratto expone sus experiencias de trabajo durante los últimos años orientadas a dar cuenta de tres objetivos principales. En primer lugar, analizar las libretas de campo de Max Uhle, depositadas en el Instituto Iberoamericano (Berlín, Alemania), las que contienen notas, observaciones y datos sobre los lugares y sitios arqueológicos que visitó en su campaña a Tinogasta en 1893, además de distintas materialidades recuperadas y depositadas en el Museo Etnológico de Berlín; en conjunto, estas informaciones cobran sentido interpeladas desde el quehacer arqueológico actual, tanto para programar nuevas prospecciones como para re-intervenir los sitios registrados y parcialmente explorados por el arqueólogo alemán. En segundo lugar, ponderar el potencial de información contenida en la documentación epistolar del jesuita Oscar Dreidemie, en tenencia de los vecinos del pueblo de Medanito (depto. Tinogasta, Catamarca), para dilucidar el derrotero y destino final de una parte de la colección de piezas arqueológicas recuperadas en las excavaciones que allí realizara a fines y comienzo de la década de 1940 y 1950, respectivamente. En tercer lugar establecer un diálogo entre la evidencia arqueología obtenida en sus investigaciones y las fuentes coloniales del período temprano para generar hipótesis acerca de la localización geográfica del "pueblo de indios de Abaucán" y otros comarcanos al momento de la conquista, sobre los que no quedaron ulteriores indicios.

2 En este trabajo se destaca la originalidad del giro metodológico realizado por Ratto sobre los antecedentes de un área de estudio, realmente inusuales con este nivel de complejidad. Los arqueólogos han recurrido con frecuencia a consultar las libretas de campo y las colecciones de las investigaciones previas pero esta aproximación a la subjetividad de sus antecesores, a sus formas de interpretar los datos y establecer una red de vínculos entre objetos, condiciones de los hallazgos, notas y correspondencia epistolar le permite a Ratto analizar mucho más a fondo los resultados de sus propias investigaciones. 
3 También es significativo que la investigación se proponga recuperar y analizar la información producida por un arqueólogo excepcional como Max Uhle, uno de los más lúcidos pioneros de la arqueología sudamericana, en especial en área andina. La minuciosa encuesta realizada por Ratto en Berlín le ha permitido articular los objetos recuperados, sus condiciones de hallazgos, y releer a la luz de esta información material y documentar las condiciones e interpretaciones alternativas que pueden desentrañarse de las ocupaciones prehispánica y colonial de la región. El relevamiento de los sitios inspeccionados por Uhle y las condiciones actuales de ese "paisaje" arqueológico aportan evidencias sobre las modificaciones ecológicas y antrópicas soportadas por la región. Todo ello matizado por información etnográfica recopilada entre los pobladores, método por el cual Ratto puede reconstruir una secuencia cronotópica de los resultados de sus investigaciones actuales.

4 Las investigaciones de Uhle y las posteriores del jesuita Oscar Dreidemie en la misma región condujeron a Ratto a discutir junto a Roxana Boixadós acerca de la localización de los pueblos de indios prehispánicos y coloniales, en una aproximación interdisciplinaria entre arqueología $-y$ la propia historia de la arqueología - y la etnohistoria, resultado del análisis de fuentes coloniales. Otro aspecto relevante de esta investigación ha sido la infatigable búsqueda de los materiales recolectados por Dreidemie a través de pistas que le permitieron localizarlas en un depósito de la USAL, y la vinculación entre los aportes del jesuita y los del arqueólogo alemán permitiendo cerrar un círculo interpretativo bien sustentado y novedoso.

5 En relación con la ocupación o intervención incaica en la región que estudia Ratto, me gustaría hacer un comentario adicional, fruto de los recuerdos de mis primeras investigaciones interdisciplinarias. Siempre tuve la intuición -y nunca me ocupé a fondo de tratar de demostrarla - de que el topónimo Chile, aplicado a la ocupación prehispánica de la zona transandina en Copiapó, se extendía hacia el sur incluyendo también el sector cisandino desde La Rioja a Cuyo, al menos a partir de la intervención incaica en esta región de frontera surandina. $\mathrm{O}$ sea, ese territorio actualmente comprendido en nuestro país, también era concebido como Chile y tal vez a eso se deba el nombre que toma el sitio inca del norte de La Rioja, Chilecito. Esta evocación se relaciona con que los sitios incas de esta franja occidental del territorio argentino incluyen materiales cerámicos de estilos de las poblaciones trasandinas (¿se trata de mitimaes chilenos?), a diferencia del resto de los sitios incas del NOA. Este rasgo diferenciador obliga a formular otras preguntas: ¿Por qué Pedro de Valdivia envía expediciones hacia el Tucumán? ¿Por qué, hasta las reformas borbónicas, Cuyo fue parte de Chile? Quizá Max Uhle hubiera podido responder algunas de estas preguntas que dejo aquí planteadas.

Vemos así que Ratto dialoga con varios interlocutores: dos arqueólogos antecesores, una etnhoistoriadora, el paisaje y los pobladores rurales actuales de la región bajo estudio. Fruto de estos diálogos polifónicos es la apertura de una problemática sugerente y plena de nuevas hipótesis de investigación.

Por su parte, la propuesta de José María Vaquer otorga una dimensión teórica general a la de Norma Ratto, ofreciendo un sustento filosófico al quehacer sustancial del arqueólogo, desde una perspectiva dialógica entre la información recuperada, la dinámica del tiempo y el horizonte subjetivo que conduce a la interpretación. Así la información recuperada se transforma en evidencia condicionada por el contexto desde el cual parte el investigador. 
8 La hermenéutica permite indagar sobre cuestiones fundamentales de una investigación: qué ve el investigador, desde dónde lo ve, hacia dónde conduce su interpretación. Los prejuicios -o comprensión previa- tienen el valor de "condiciones trascendentales del entender", dice Gadamer. Vaquer sostiene que no siempre el arqueólogo considera la situación contextual en la que se realizada una investigación. Las interpretaciones de la información pasan de ser un aparente hecho objetivo a una evidencia solo tras ese proceso de interpretación condicionado por su tiempo y espacio. Los hechos nunca hablan por sí mismos, no encierran un leguaje autónomo sino que necesitan que el investigador cumpla el rol del ventrílocuo. Y sólo si comprende que su rol está fuertemente condicionado por su o sus experiencias previas, puede advertir que lo que considera una evidencia objetiva es apenas relativa a su tiempo y a su espacio. La objetividad que propugnaba la arqueología procesual entró en crisis en la medida en que se reconoce que toda interpretación pre-supone un contexto subjetivo del investigador. Así, "el pasado es el producto de una interpretación situada en el presente".

9 Tanto la arqueología - como uno de los posibles métodos para hacer historia- y la antropología se desarrollan simultáneamente entre el pasado y el presente. El estar "situado" en el presente condiciona o guía la interpretación del pasado, pero el pasado también permite comprender el presente. 0 , si queremos, el presente sólo es entendible si consideramos su respectivo pasado. $Y$ esto es posible únicamente si el investigador toma conciencia de esta situación hermenéutica en la que está inserto. "El pasado es la condición de posibilidad del presente", recuerda Vaquer. Como bien sabemos, los historiadores ya han desarrollado esta perspectiva; es el "Futuro Pasado" de Koselleck. Todo ello contiene una dimensión política, pues toda interpretación es construida desde una perspectiva particular, con intereses particulares.

De más está decir cómo influye este condicionamiento "situacional" en la "lectura" de la producción previa, en la comprensión de lo que escribe un autor. ¿En qué contexto nuevamente situacional- las interpretaciones de un autor se convierten en, por ejemplo, un "modelo"? El trabajo de Vaquer sugiere nuevas preguntas: ¿Por qué en determinado momento una evidencia adquiere rango de verdad probada e indiscutible $\mathrm{y}$, con el paso del tiempo, nueva información y por lo tanto nuevas evidencias, permiten poner en cuestión el "modelo"? ¿Qué formación tiene un autor, cuáles son sus interlocutores del momento, de qué técnicas dispone y cómo una cierta recurrencia de datos permite extenderlo hasta proponer una generalización, pasando por alto los matices? ¿La recurrencia es sinónimo de homogeneidad?

11 Vaquer hace notar que siempre hay una lucha de poderes en las interpretaciones y que el medio académico en el que se producen estas interpretaciones nunca es neutro. Se pregunta si es legítimo interrogarse sobre lo que "en verdad" pasó. De allí que para evitar una cierta deslegitimación de la verdad siempre es útil el trabajo interdisciplinario que colabora en contrastar perspectivas y recorrer el mismo camino con vehículos distintos. Además permite evitar algo que se produce con frecuencia: una cierta violencia epistémica, que condiciona local, region o, aun, universalmente, determinadas líneas de interpretación. Es lo que alguna vez leí en un número de la revista American Archaeology: los riesgos de ejercer terrorismo intelectual. El que no está de acuerdo conmigo es mi enemigo y la mejor manera de neutralizarlo es ignorarlo, o sea decretar su muerte académica. La interdisciplina, por su apertura y proyección hacia otros campos, ofrece algunos resguardos a estos contingentes infortunios (tengo anécdotas personales con respecto a estos temas). 


\section{AUTHOR}

\section{ANA MARÍA LORANDI}

Universidad de Buenos Aires-Consejo Nacional de Investigaciones Científicas y Técnicas (CONICET), Argentina

Correo electrónico: anamarialorandi@gmail.com 